\title{
Assessment of ecosystem health of tropical shallow waterbodies in eastern India using turbulence model
}

\author{
N. R. Samal, ${ }^{1, *}$ A. Mazumdar, ${ }^{2}$ K. D. Jöhnk ${ }^{3}$ and F. Peeters ${ }^{4}$ \\ ${ }^{1}$ Dept. of Civil Engineering, National Institute of Technology Durgapur, Durgapur -713 209, West Bengal, India \\ ${ }^{2}$ School of Water Resources Engineering, Jadavpur University, Kolkata - 700 032, West Bengal, India \\ ${ }^{3}$ Leibniz-Institute of Freshwater Ecology and Inland Fisheries, Alte Fischerhütte 2, 16775 Neuglobsow, Germany. \\ ${ }^{4}$ Limnologisches Institut, University of Konstanz, 78457 Konstanz, Germany \\ ${ }^{*}$ Corresponding author: nihar_samal@yahoo.co.in; nihar.samal@nitdgp.ac.in
}

In the present study, a numerical model of the hydrodynamic and thermal structure of artificial shallow lakes in eastern India has been developed as a tool to assess the ecological water quality, driven by the meteorological forcings. It allows quantification of the vertical mixing processes that govern not only the thermal structure but also nutrient exchanges and the distribution of dissolved and particulate matter among water layers. Vertical temperature profiles were calculated by solving coupled partial differential equations for temperature (heat energy balance equation), one-dimensional momentum equation and a second order closure scheme for small-scale turbulence effects, i.e. turbulent kinetic energy and turbulent dissipation rates numerically using an implicit time integration method. The effect of advection due to the inflow and outflow is not taken into consideration as these shallow waterbodies are assumed to behave as a closed lake. The oxygen level measured at different layers during the simulation period in these waterbodies reflects hypolimnetic oxygen depletion due to the thermal stratification in the aquatic environment. The changes in the stratification regime in these waterbodies are expected to affect the water quality and the health of the ecosystem, primarily based on temperature and dissolved oxygen parameter and in particular, the certain features of the oxygen resources of the hypolimnion.

Keywords: thermal stratification, mixing, hypolimnetic oxygen depletion

\section{Introduction}

Lakes, or in general waterbodies, are extremely important freshwater storage on the Earth's surface. Their ecosystem service functions are equally important in terms of sustainable, economic and social development. However, continuous inputs of various forms of chemical pollution from a variety of human activities have seriously deteriorated the health status of many lake ecosystems around the globe. If this trend continues, it may not only affect human health and social-economic development, but could lead to the collapse of lake ecosystems as a whole (Cairns, 1997). A number of indicators of lake ecosystem health assessment have been proposed, e.g. ecosystem stress indicators by Rapport et al., 1985, inhibitory analysis of top-down control approach and the polyfunctional role of biodiversity in processes leading to water self-purification by Ostroumov, $(2002,2002 a)$, thermodynamic indicators including exergy and structural exergy by Jorgensen (1995b), and a set of comprehensive ecological indicators covering lake structural, functional and system-level aspects by Xu et al. $(1999,2001 a)$. An additional set of methods and procedures proposed for assessing lake ecosystem health include, 
a tentative procedure by Jorgensen (1995b), and the direct measurement method (DMM) and an ecological modeling method (EMM) by Xu et al. (2001a, b). First, it is extremely difficult to assess the actual health status of a lake/waterbody ecosystem - only the relative health status has been evaluated; and secondly, it has been impossible to make comparisons of ecosystem health status among different lakes (Xu et al., 2001a). Assessment of lake ecosystem health from the point of view of dying aquatic organisms (such as fish kill) in tropical regions are frequently attributed to low dissolved oxygen concentrations; however the circumstances causing these events vary considerably (Simon et al., 1992). In the present study, the primary objective is to propose a one-dimensional modeling approach under limited physico-chemical data, based on the meteorological forcings for assessing the ecosystem health of two shallow tropical lakes in the Kolkata city of India. While the validation of the model is made with the discrete temperature data over 2249 Julian days to predict the extensive continuous hourly thermal profiles indicating the hydrodynamical events such as stratification as well as mixing throughout that periods, in turn, the predicted thermal profiles would reveal the oxygen status at different limnetic layers in these waterbodies with particular reference to the hypolimnetic oxygen depletion. There is no effort from the lake authority or any other governmental agency to survey and monitor the water quality of the lakes regularly and keep records of such data chronologically, which is why it is more appropriate to utilize and implement a modeling approach to predict the health status with regard to temperature and dissolved oxygen with limited data measured during the limnological investigation. Thus changes in the stratification regime in these waterbodies play the dominant role apart from biological purification (Ostroumov 2002, 2002a) in predicting the water quality and health of the ecosystem, in particular, the oxygen resources of the hypolimnion.

\section{Materials and methods}

\section{Lake characteristics and data acquisition study site}

In the present investigation, comparatively shallow and deep lake such as Rabindra Sarobar and Subash Sarobar in the Kolkata city is chosen. The Rabindra Sarobar $\left(22^{\prime} 34^{\prime} \mathrm{N}, 88^{\prime} 23^{\prime} \mathrm{E}\right)$, a rather small and shallow but highly eutrophic lake is located in the southern part of the metropolis of Kolkata spread over an area of $780,700 \mathrm{~m}^{2}$ having water area of $295,400 \mathrm{~m}^{2}$ (or about $38 \%$ of the land area). There are three lakes within the area of Rabindra Sarobar complex and the larger waterbody of the three (i.e. basin $-\mathrm{K}$ ) has a surface area of about 171,000 $\mathrm{m}^{2}$ and contains three small islands (Figure 1). The mean length and width of the basin -K (Figure 1) are $1080 \mathrm{~m}$ and $184 \mathrm{~m}$ respectively while its maximum depth and the mean depth are $5.7 \mathrm{~m}$ and 3.5 $\mathrm{m}$ respectively. The Subhas Sarobar (Latitude $22^{\circ}$ $34^{\prime}-22^{\circ} 34^{\prime} 30^{\prime} ' \mathrm{~N}$ and Longitude $88^{\circ} 24^{\prime}-88^{\circ} 24^{\prime}$ $30^{\prime \prime} \mathrm{E}$ ), along with its two islands, one small and the other big, represents the lung of East Kolkata within the concrete jungle of the metro city. The surface area of Subhas Sarobar (Figure 1) is about $160,000 \mathrm{~m}^{2}$. The maximum length and width of the Lake are $617 \mathrm{~m}$ and $352 \mathrm{~m}$ respectively while the maximum depth and the mean depth of the lake are $10 \mathrm{~m}$ and $4.8 \mathrm{~m}$, respectively. The waterbody is given on rent to the Department of Fisheries of Government of West Bengal state, which mainly serves the livelihood of the surrounding people through fishing. Over three thousand people per day use this lake water for washing clothes and utensils and for bathing.

\section{Lake temperature and dissolved oxygen data}

The observation sites were selected considering the maximum water depth along the mid-reach, which are also least influenced by human intervention, to study the thermal stratification and its impact on lake ecosystem. The measurement of temperature and dissolved oxygen profiles in the basin -K of Rabindra Sarobar have, however, been started during the month of November, 2000 and in Subhas Sarobar during May, 2003 using a duly calibrated WTW temperature/oxygen meter along the depth at an interval of $0.5 \mathrm{~m}$ below the water surface till February, 2005, thus providing detailed information on the temperatures and dissolved oxygen level prevailing in all depth regions of the lake. All the measured temperature and dissolved oxygen data are considered to be accurate to within $\pm 0.1^{\circ} \mathrm{C}$ and \pm 0.01 ppm respectively.

\section{Meteorological data}

The daily meteorological data, i.e. maximum and minimum air temperature, maximum and minimum 


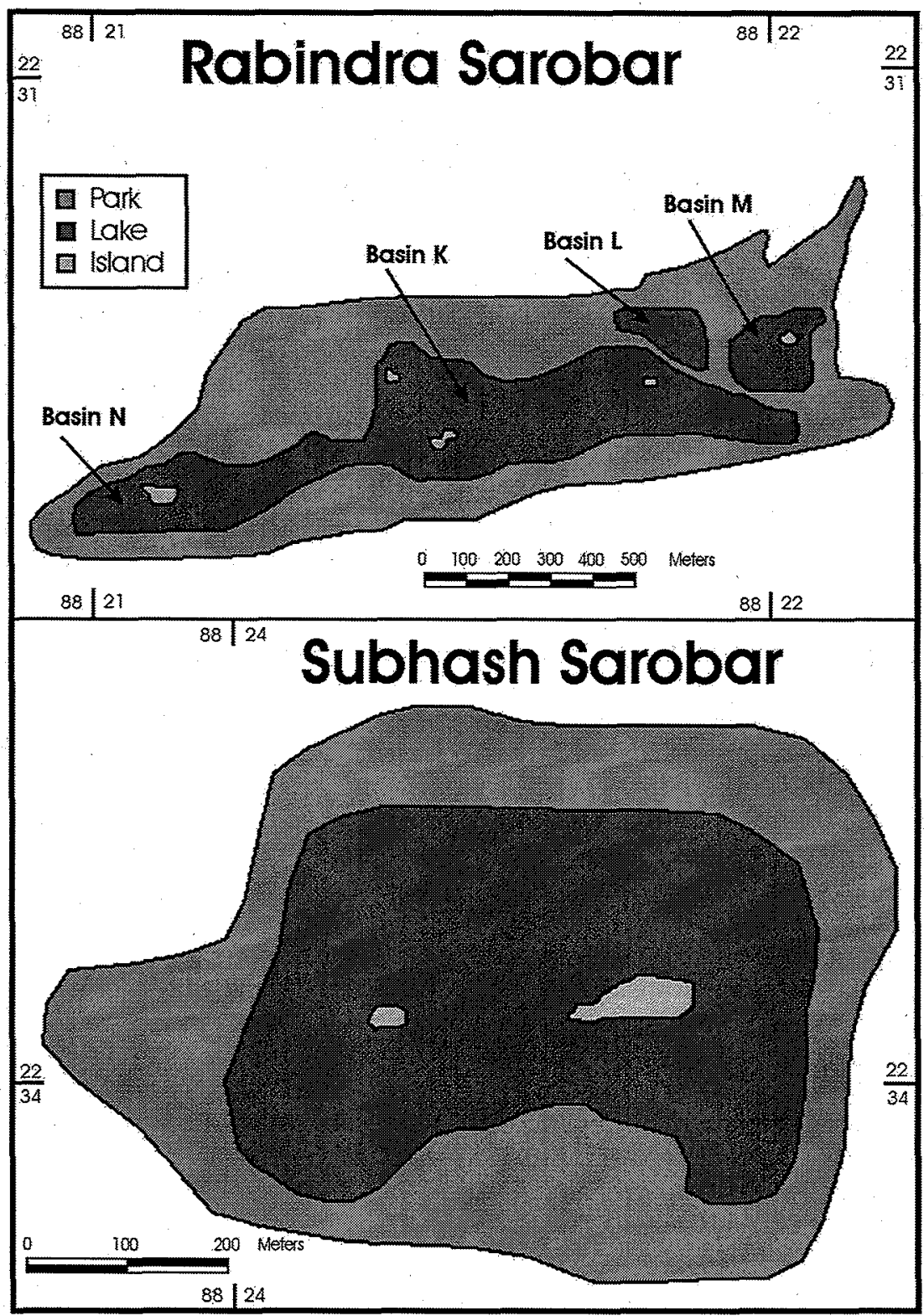

Figure 1. Sampling stations map of two tropical lakes in India

relative humidity, mean wind speed and mean cloud cover were supplied by the nearest meteorological station (Kolkata), such as Alipore (for lake Rabindra Sarobar) and Dumdum (for lake Subhas Sarobar) in Kolkata city. In order to take adequate account of the diurnal cycle in meteorological forcing, which may be important for the long-term development of the thermal structure of the lake, the meteorological data are interpolated at hourly intervals using the empirical equations, which are described somewhere else (Jöhnk and Umlauf, 2001; Hutter and Jöhnk, 2004; Samal, 2004a). The hourly values of the global irradiance are calculated depending on the course of the sun from the geographical position, cloud cover, $\mathrm{C}$, and wind speed, U. As the solar radiation is absorbed within the water column rather than at the air-water interface, the vertical distribution of heat depends not only on vertical mixing processes, but also on light extinction coefficient. The extinction coefficient for clear water is 
determined by the empirical formula given in Jöhnk and Umlauf (2001):

$$
\mathrm{K}_{\mathrm{cw}}=1.7 / \mathrm{Z}_{\text {sechi }},
$$

Using the maximum measured Secchi-depth of $Z_{\text {secchi }}=1.5 \mathrm{~m}$ for lake Rabindra Sarobar and $1.7 \mathrm{~m}$ for lake Subhas Sarobar during our observation period, yields the clearwater extinction of $\mathrm{K}_{\mathrm{cw}}$.

\section{Model development and validation}

In one dimensional lake water quality modelling, different models do emphasize different physical processes and make rather crude assumptions about the mixing processes. A more general model of the problem has to include all the relevant physical processes and especially be able to describe the mixing due to turbulence in a realistic way. Since accurate descriptions of the temperature and the diffusivities are crucial for the study of underwater dynamics in lake ecosystems, we consider $k-\varepsilon$ models as the best choice for the present investigation. The $(\mathrm{k}-\varepsilon)$ turbulence model is designed taking the turbulence closure scheme into account, where rates for vertical transport are not directly parameterized by external forces but are related to the turbulent kinetic energy (Kraus and Turner, 1967). This model is derived from hydrodynamical equations and is able to simulate transport processes quite accurately with high temporal resolution but is more difficult to develop and calculations are more time consuming. However, models of this type allow predictions of the effect of climate change on vertical mixing and also the interaction of chemical, biological and physical processes could be studied (Goudsmit et al., 2002). The principles of this model (i.e. LakeOneD) is based on the solution of coupled partial differential equations for the temperature (e.g. heat balance), horizontal flow velocities (e.g. momentum equation) and a second-order closure scheme for the small-scale turbulence effects, i.e., turbulent kinetic energy, $k$, and turbulent dissipation rates, $\varepsilon$, which can be used to describe the vertical temperature structure and mixing (Svensson, 1978; Rodi, 1993). The relevant governing equations included in LakeOneD (Jöhnk and Umlauf, 2001; Hutter and Jöhnk, 2004) are listed in Table 1. It is driven by the meteorological fields and determines temperature, turbulent kinetic energy and turbulent dissipation rates on a depth grid with $\mathrm{dz}=0.25 \mathrm{~m}$ and on time steps of 4 minutes. The equations for temperature, turbulent kinetic energy and its dissipation together with the balance equations for momentum in horizontal direction are solved numerically using an implicit time integration method. The hydrodynamical model or in detail the $(\mathrm{k}-\varepsilon)$ turbulence model is thereby extended to postulate the thermal stratification and mixing in shallow or deep lake in the tropics. The prediction by model needs validation by historical data and once validated it could be utilized for prediction with limited data input and that is why the model has the speciality of depicting the ecohealth with minimum measured input thereby reducing the lake authority's effort (which are rarely found in Govt./Semi Governmental structure) to a minimum as regards to data collection.

\section{Results and discussion}

\section{Temporal distribution of lake water temperature}

The model run is initialised by applying the prescribed atmospheric forcing to a stationary waterbody at uniform temperature, close to the average air temperature. The model is calibrated by comparing the results of simulations with measurements of long-term historical temperature data for both lakes (Figs. 2 and 3). The figures show a good overall agreement to the measured data. It may be noted that the simulation is run with respect to the deepest point of the station in the lake (i.e. $5.7 \mathrm{~m}$ for lake Rabindra Sarobar and $9.5 \mathrm{~m}$ for lake Subhas Sarobar) and a simple quantification of the goodness of simulated results for individual profiles at different stations within the lake are obtained by minimising the mean squared error (MSE).

$$
\mathrm{MSE}=\frac{\sum_{i=1}^{n}\left(T_{m e s, i}-T_{\text {sim }, i}\right)^{2}}{N},
$$

Where $\mathrm{N}=$ number of observations.

The minimum value of MSE represents a good agreement between the measured and the simulated data for temperature. Some discrepancies between the measured and the estimated temperature profiles have been observed on a few occasions in both lakes, especially in the surface and bottom layers. The low temperature (i.e. about $16.8^{\circ} \mathrm{C}$ ) in the bottom layers as observed in the first profile of the measured data as compared to profiles of 
Table 1. Governing equations of the $k-\varepsilon$ turbulence model in LakeOneD (Jöhnk and Umlauf, 2001; Hutter and Jöhnk, 2004):

Governing equations of the $k-\varepsilon$ turbulence model Constants of the $\mathrm{k}-\varepsilon$ model:

in LakeOneD (Jöhnk and Umlauf, 2001; Hutter and $c_{\mu}=0.09,1=1.44,2=1.92$,

Jöhnk, 2004):

$$
\begin{aligned}
& \frac{\partial T}{\partial t}=\frac{1}{A} \frac{\partial}{\partial z}\left(A\left(D^{(T)^{\prime}}+D^{\prime}\right) \frac{\partial T}{\partial z}\right) \\
& +\frac{1}{\rho c_{p}}\left[\frac{\partial I}{\partial z}+\frac{1}{A} \frac{\partial A}{\partial z} q_{g e o t h}\right] \\
& \frac{\partial u}{\partial t}=\frac{1}{A} \frac{\partial}{\partial z}\left(A\left(D^{(T)}+D\right) \frac{\partial u}{\partial z}\right)+f v \\
& \frac{\partial v}{\partial t}=\frac{1}{A} \frac{\partial}{\partial z}\left(A\left(D^{(T)}+D\right) \frac{\partial v}{\partial z}\right)-f u \\
& \frac{\partial k}{\partial t}=\frac{\partial}{\partial z}\left(D^{(k)} \frac{\partial k}{\partial z}\right)+P+G+\varepsilon \\
& \frac{\partial \varepsilon}{\partial t}=\frac{\partial}{\partial z}\left(D^{(\varepsilon)} \frac{\partial \varepsilon}{\partial z}\right)+\frac{\varepsilon}{k}\left(c_{1} P+c_{3} G-c_{2} \varepsilon\right) \\
& P=D^{(T)}\left[\left(\frac{\partial u}{\partial z}\right)^{2}+\left(\frac{\partial v}{\partial z}\right)^{2}\right] \\
& G=-\frac{D}{\sigma_{T}} \frac{\partial \rho}{\rho} \frac{\partial z}{Q_{n e t}}=Q_{s}+Q_{l i n}+Q_{l o u t}+Q_{e}+Q_{c} \\
& D^{(\varepsilon)}=\frac{D^{(T)}}{\sigma_{\varepsilon}} \\
& D^{(T)}=c_{\mu} \frac{k^{2}}{\varepsilon}, \\
& D^{(T)^{\prime}}=\frac{D^{(T)}}{\sigma_{T}}, \mathrm{U}_{10}^{2} \\
& D^{(k)}=\frac{D^{(T)}}{\sigma_{k}}, \\
& Q^{\prime}
\end{aligned}
$$

$c_{3}=0.8 \sigma_{k}=1.0$ and $\sigma_{\varepsilon}=1.3$

Definitions:

$T \quad$ Temperature $\left({ }^{\circ} \mathrm{C}\right)$

$u \quad$ Horizontal velocity west-east $\left(\mathrm{m} \mathrm{s}^{-1}\right)$

$v \quad$ Horizontal velocity south-north $\left(\mathrm{m} \mathrm{s}^{-1}\right)$

$k \quad$ Turbulent kinetic energy per unit mass ( $\mathrm{J}$ $\mathrm{kg}^{-1}$ )

$\varepsilon \quad$ Dissipation rate of $k\left(\mathrm{~W} \mathrm{~kg}^{-1}\right)$

$D \quad$ Molecular viscosity, $1.5 \times 10^{-6} \mathrm{~m}^{2} \mathrm{~s}^{-1}$

$D^{\prime} \quad$ Molecular diffusivity, $1.5 \times 10^{-7} \mathrm{~m}^{2} \mathrm{~s}^{-1}$

$D^{(T)} \quad$ Turbulent viscosity $\left(\mathrm{m}^{2} \mathrm{~s}^{-1}\right)$

$D^{(T)^{\prime}} \quad$ Turbulent diffusivity $\left(\mathrm{m}^{2} \mathrm{~s}^{-1}\right)$

$D^{(K)} \quad$ Turbulent diffusivity of $k\left(\mathrm{~m}^{2} \mathrm{~s}^{-1}\right)$

$D^{(\varepsilon)} \quad$ Turbulent diffusivity of $\varepsilon\left(\mathrm{m}^{2} \mathrm{~s}^{-1}\right)$

$P \quad$ Production of $k$ due to shear stress (W $\mathrm{kg}^{-1}$ )

$G \quad$ Buoyancy production of $k\left(\mathrm{~W} \mathrm{~kg}^{-1}\right)$

$t \quad$ Time (s)

$C_{P} \quad$ Specific heat of lake water $\left(\mathrm{J} \mathrm{kg}^{-1} \mathrm{k}^{-1}\right)$

$\rho \quad$ Density of lake water $\left(\mathrm{kg} \mathrm{m}^{-3}\right)$

$f \quad$ Coriolis parameter $\left(\mathrm{s}^{-1}\right)$

$z \quad$ Depth (positive upward) (m)

A Cross-sectional area at $\mathrm{z}\left(\mathrm{m}^{2}\right)$

$I \quad$ Short-wave solar radiation at $\mathrm{z}\left(\mathrm{W} \mathrm{m}^{-2}\right)$

$Q_{\text {net }} \quad$ Net heat flux between atmosphere and water $\left(\mathrm{W} \mathrm{m}^{-2}\right)$

$Q_{s} \quad$ Heat flux due to shortwave radiation (W $\mathrm{m}^{-2}$ )

$Q_{\text {lin }} \quad$ Heat flux due to longwave radiation in (W $\mathrm{m}^{-2}$ )

$Q_{\text {out }}$ Heat flux due to longwave radiation out $\left(\mathrm{W} \mathrm{m} \mathrm{m}^{-2}\right)$

$Q_{e} \quad$ Heat flux due to evaporation or condensation ( $\mathrm{W} \mathrm{m}^{-2}$ )

$Q_{c} \quad$ Heat flux due to conduction $\left(\mathrm{W} \mathrm{m}^{-2}\right)$

$\tau$ Flux of momentum from the wind to the water

$\mathrm{U}_{10} \quad$ Wind speed $10 \mathrm{~m}$ above the surface

$\rho_{a} \quad$ Density of air

$C_{D 10}$ Drag coefficient $\left(1.3 \times 10^{-3}\right)$ other dates in the lake Subhas Sarobar and also in the 6 th, 8 th and 10 th profiles in the lake Rabindra Sarobar is due to some exchange flow, which might be due to internal oscillations in lake (Samal et al., 2008). This also indications a shifting of the thermocline and in turn may be due to the low vertical transport of heat brought about by large density gradients.

The seasonal Temperature-Depth (T-D) profiles during the simulation period (January 1999February 2005) in both lakes can well be defined from the model output (Samal, 2006). From the 

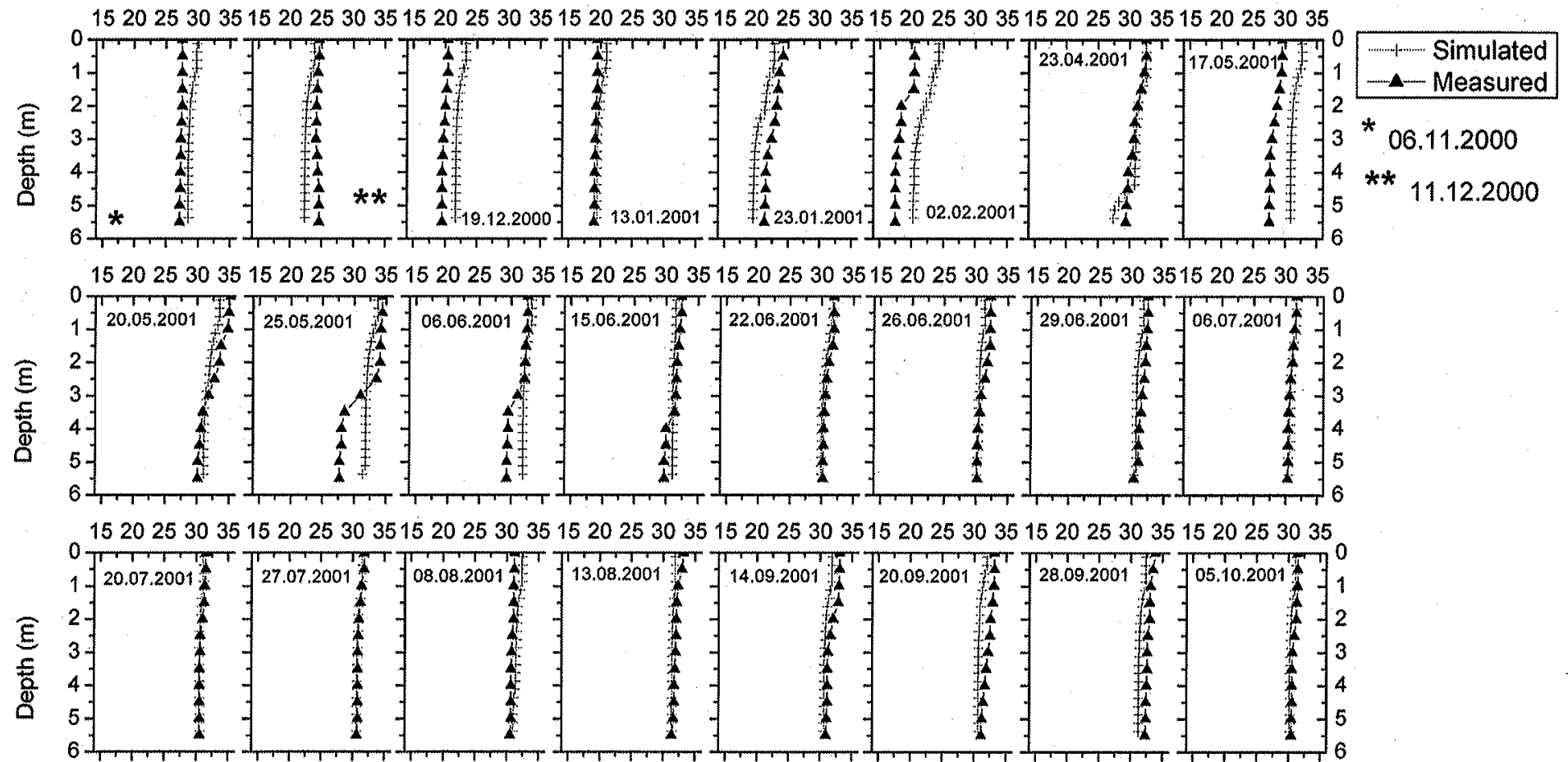

Temperature $\left({ }^{\circ} \mathrm{C}\right)$

Temperature $\left({ }^{\circ} \mathrm{C}\right)$

Temperature $\left({ }^{\circ} \mathrm{C}\right)$

Figure 2. Simulated and measured temperature profiles for lake Rabindra Sarobar (Basin - K) 

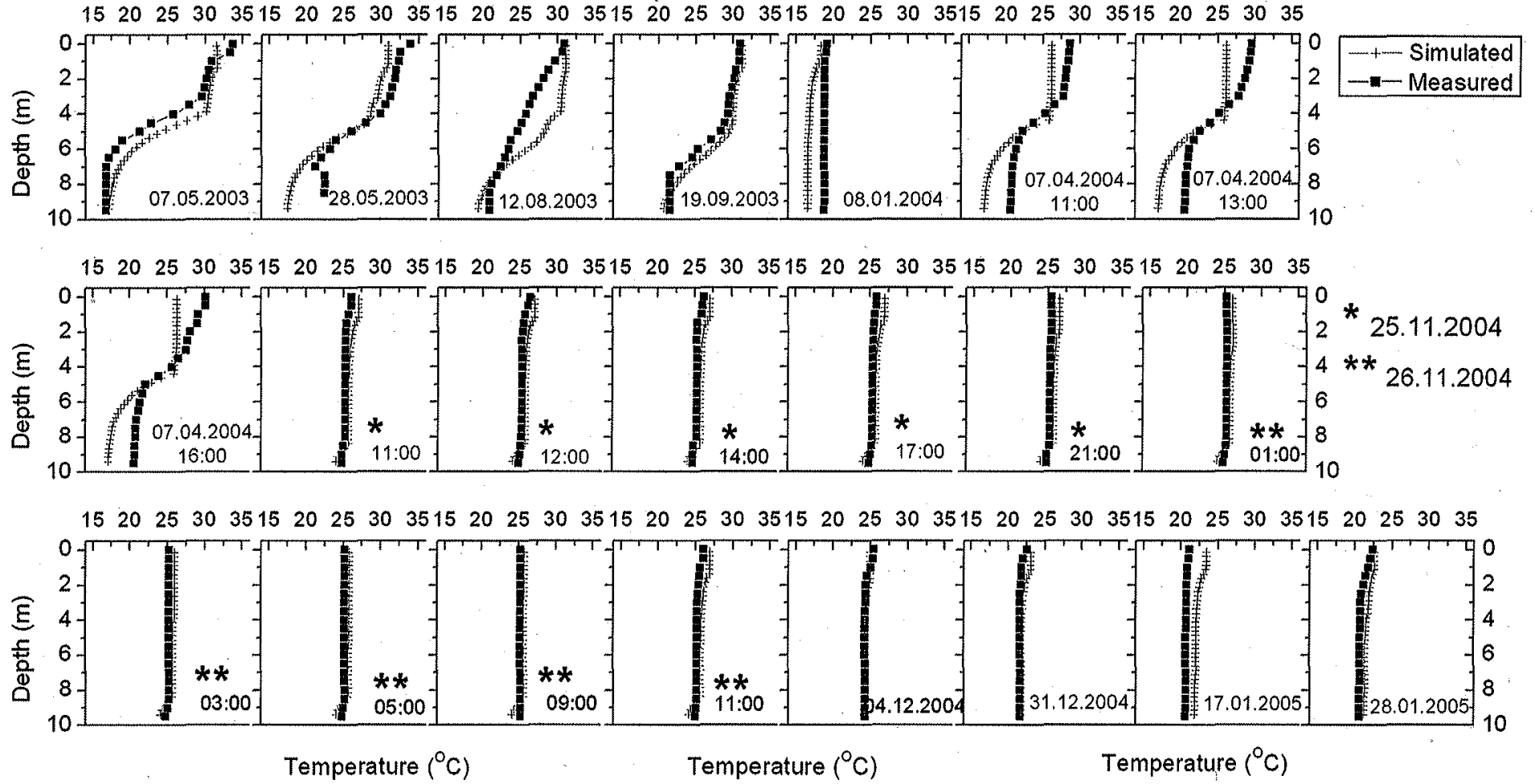

Figure 3. Simulated and measured temperature profiles for lake Subhas Sarobar 
(T-D) distributions (Fig. 2 and 3), it is clear that during a year the stratification begins to form mainly in March and the thermocline gradually deepens, this downward movement completely disappears by the end of May, the period of peak summer in the tropics. A well defined seasonal thermocline is formed in March with a small hypolimnion and the increasing solar radiation as well as the wind stress deepens the upper mixing layers as a result the hypolimnion becomes thin. This coincides with the erosion of the thermocline, as the water layers attain complete mixing state. Gradual mixing of the epilimnion progresses and attains a stable mixed layer during May and the low mixing in the epilimnion at the beginning of the year shows a multiple thermocline as also observed by other authors (Imberger et al., 1981). The mixing period may be an implication of better water quality due to the movement of the upper oxygen rich layer towards the bottom layer. The basin $-\mathrm{K}$ of Rabindra Sarobar remains completely mixed (about 8 months) from surface to bottom with no intermittency from mid-June to February till the next onset of thermal stratification, which begins each year from March to mid-June (summer period) (Fig. 2) showing the nature of a polymictic lake, while, the lake Subhas Sarobar under different meteorological forcings and different morphometric conditions exhibits a longer stratification period (from February to October: about 9 months) and mixes only during the cold period (Fig. 3), which implies a warm monomictic lake. Identification of the stratification and mixing period obtained from this model over six years of simulation is central to understanding the vertical distribution of dissolved oxygen during these periods, which might have greater influence on changes to the aquatic ecosystem health of the lake.

\section{Temporal distribution of dissolved oxygen}

Dissolved oxygen (DO) has been one of the most important and measured water quality parameters since the study of limnology or for that matter, study of water quality of natural water sources began. However, apart from temperature stratification, very few investigations have dealt with the processes of redistribution of dissolved oxygen during periods of density stratification, nor have they dealt with the processes controlling oxygen stratification (Verburg et al., 2003). In a stratified lake, the depletion of oxygen in the hypolimnion would cause a number of significant changes in the chemistry and biology of a lake and this feature has been substantiated recently by Prepas et al. (1997) and many other authors. The fish kills in ponds and small lakes usually occur during summer and winter stratification and are specially related to critically low oxygen levels (Simon et al., 1992; Samal et al., 2004b); however, pollution, fish diseases and a phenomenon known as turnover can also kill fish.

The surface water temperature during the simulation period in the lake Rabindra Sarobar, ranges from 19.5 to $35.2^{\circ} \mathrm{C}$ with a mean value of $30.11^{\circ} \mathrm{C}$ (SD: \pm 4.6 ), while the bottom water temperature is from 17.5 to $32.3^{\circ} \mathrm{C}$ with a mean value of $28.04^{\circ} \mathrm{C}$ (SD: \pm 4.2 ). The surface dissolved oxygen concentration (Fig. 4), varies from 7.7 to $5.7 \mathrm{ppm}$ with a mean value of around $6.6 \mathrm{ppm}$ (SD: \pm 0.6 ), while the bottom oxygen concentration remains within a range of 4.9 to $1.8 \mathrm{ppm}$ with a mean of $3.4 \mathrm{ppm}$ (SD: \pm 1.0 ). During the winter period, when the lake is almost in a complete state of mixing, the surface DO is about 7 to $8 \mathrm{ppm}$, while the bottom DO is nearly $4.17 \mathrm{ppm}$. Again during the summer period, the DO concentration decreases due to the increase in water temperature at the lake surface and the bottom gradually decreases to less than $2.47 \mathrm{ppm}$ because of the formation of the oxycline in the metalimnion (Samal and Mazumdar, 2005). In this tropical climate, the observed air and water temperature almost represent a similar and parallel change during the months of May (i.e. peak summer) and midOctober, which imply an equivalent phenomenon of oxygen depletion at the bottom to a height of about $1.0 \mathrm{~m}$. The lake Rabindra Sarobar exhibits anoxic (DO $<1 \mathrm{ppm}$ ) conditions only during the peak summer and generally to a height of $0.5-0.75 \mathrm{~m}$ from the sediment-water interface. The oxic conditions (DO $>5 \mathrm{ppm}$ ) usually occur up to a depth of $2-2.5$ $\mathrm{m}$ from the water surface with hypoxia (DO $\sim 1-5$ $\mathrm{ppm}$ ) in between. The hypoxic conditions in general exist within the oxycline layer of the water column. Over the years, the lake Rabindra Sarobar shows hypoxic conditions of dissolved oxygen except during the summer season.

The deeper lake, Subhas Sarobar, experiences a longer period of thermal stratification than mixing over the year. During the limnological sampling programme (Fig. 5), the surface water temperature varies from 33.8 to $19.1^{\circ} \mathrm{C}$ with a mean value of $26.6^{\circ} \mathrm{C}$ (SD: \pm 3.7 ), while the bottom water temperature varies from 25.2 to $16.8^{\circ} \mathrm{C}$ with a mean value of $22.6^{\circ} \mathrm{C}$ (SD: \pm 2.4 ). Again, dissolved oxygen at the surface ranges from 12.24 to $1.03 \mathrm{ppm}$ 


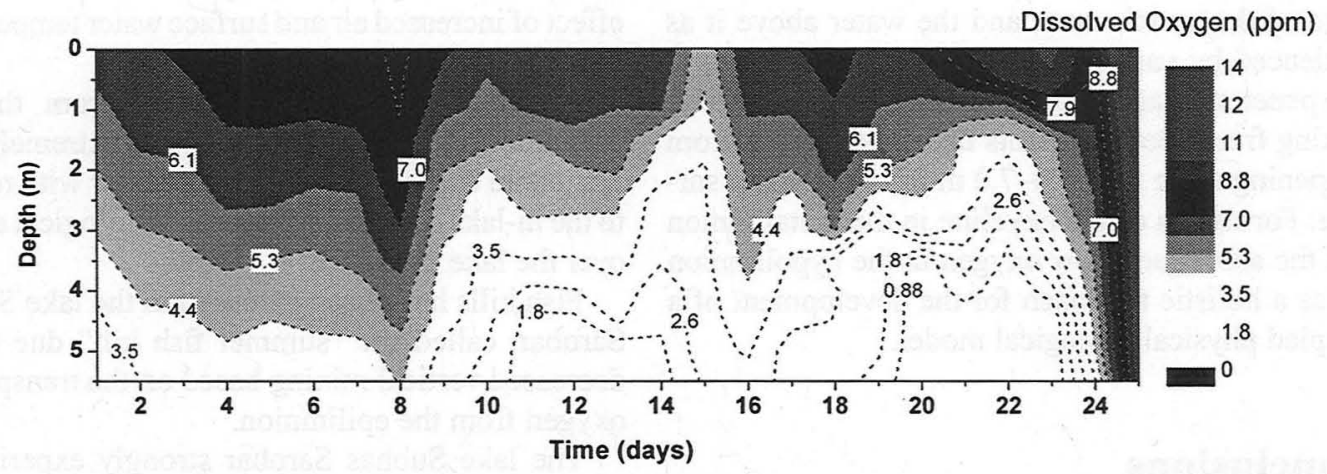

Profile date: 29/11/2001, 07/12, 21/12, 28/12/2001; 04/01, 11/01, 18/01, 02/02, 22/02, 08/03, 05/04, 26/04, $10 / 05,29 / 05,21 / 09,15 / 12 / 2002,27 / 02,29 / 04,22 / 05 / 2003,01 / 04 / 2004$ (10:00, 13:00, 15:00, 16:00), 01/12/2004, 12/01/2005

(e.g. graduation, say, 3 - implies 3rd sampling date, namely profile on 21/12/2001)

Figure 4. Isopleths of dissolved oxygen for lake Rabindra Sarobar during the simulation period

with a mean value of $6.79 \mathrm{ppm}(\mathrm{SD}: \pm 2.8)$, while at the bottom varies from 8.46 to $0.01 \mathrm{ppm}$ with a mean value of $1.76 \mathrm{ppm}$ (SD: \pm 2.6 ). The fifth profile for temperature and dissolved oxygen (i.e. on 8th January 2004) shows a well mixed temperature profile with apparent variation in dissolved oxygen level. The profile measured on 25-26th November 2004 shows the effects of diurnal changes in temperature and dissolved oxygen level. The effects of the strong earthquake of 26th December 2004 could be noticed in Subhas Sarobar during the observations carried out on 31st December 2004 and the lake also strongly experienced the effect of the Tsunami with the complete turnover of the entire mass of water, indicated by the high water temperature and the elevated oxygen level along the depth (Fig. 5), observed on 31st December 2004, and vigorous os- cillations in the water mass persisted until the last day of sampling (28th January 2005) in the limnological year. However, the oxygen level in the hypolimnion region continued to decrease to a value of $0.01 \mathrm{ppm}$ over the year together with a due effect of increased air and surface water temperature in the lake. Oxygen concentrations near the sedimentwater interface may fluctuate daily, depending on the degree of daily mixing of the epilimnion.

From six years of observations, it may be stated that the average depth of anoxia in lake Subhas Sarobar is approximately 1.0 to $1.5 \mathrm{~m}$ from the lake bottom; however, the depth of the oxycline showed considerable short-term and long-term fluctuations above the anoxic layers and below the oxic layers $(2.0-2.5 \mathrm{~m})$ from the lake surface. There seems to be a frequent exchange of oxygen between the upper

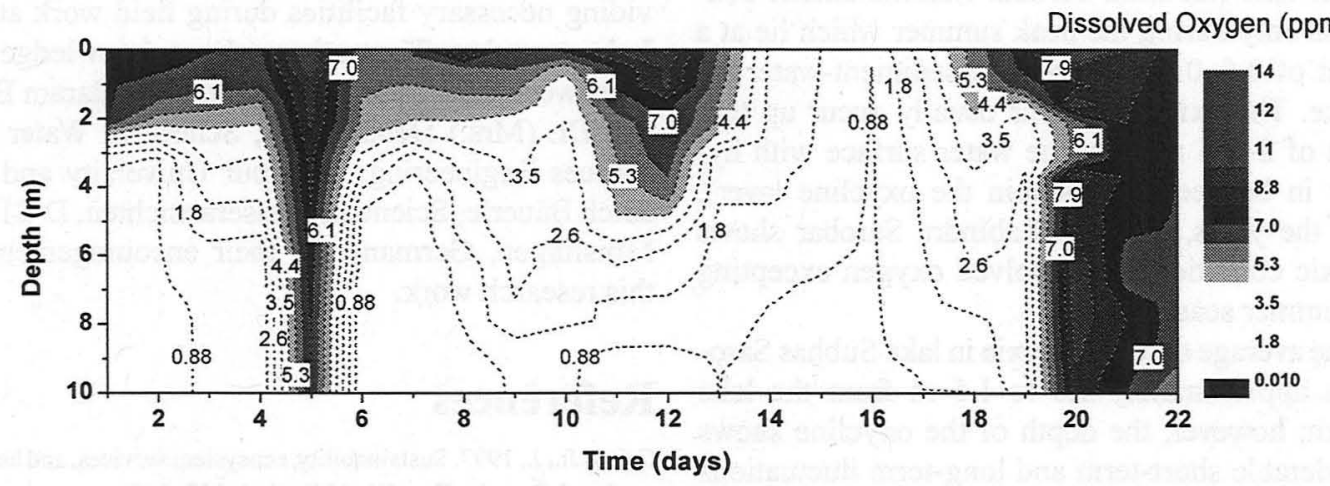

Profile date: $07 / 05,28 / 05,12 / 08,19 / 09 / 2003,08 / 01,07 / 04 / 2004$ (11:00, 13:00, 16:00), 25/11/2004 (11:00, 12:00, 14:00, $17: 00,21: 00), 26 / 11 / 2004$ (01:00, 03:00, 05:00, 09:00, 11:00), 04/12/2004, 31/12/2004, 17/01/2005, 28/01/2005

(e.g. graduation, say, 3 implies 3 rd sampling date, namely profile on 12/08/2003)

Figure 5. Isopleths of dissolved oxygen for lake Subhas Sarobar during the simulation period 
edge of the anoxic zone and the water above it as evidenced by variation in the depth to which oxygen penetrates, and this is because of the epilimnetic mixing from above prevents the anoxic layers from deepening more than $6.0-7.0 \mathrm{~m}$ from the water surface. Formation of the oxycline in the metalimnion and the subsequent low oxygen in the hypolimnion needs a holistic approach for the development of a coupled physical-biological model.

\section{Conclusions}

Temperature and DO profiles provide sufficient information to characterize the state of turbulence, potential of mixing and depletion of oxygen in the hypolimnion, which is a measure and sufficient indication of the ecosystem health of a lake/waterbody. The underlying thermomechanical variables obtained from this $(\mathrm{k}-\varepsilon)$ turbulent closure give good insight in to the processes driving the hypolimnetic oxygen depletion which is clearly observed from the measured data of dissolved oxygen during the stratification and mixing period. Thus the major conclusions of this study include the following:

The basin $-\mathrm{K}$ of Rabindra Sarobar remains completely mixed (about 8 months) from mid-June to February until the onset of thermal stratification (from March to mid-June: summer period), showing the nature of a polymictic lake, while, the lake Subhas Sarobar under different meteorological forcings and different morphometric conditions exhibits a longer stratification period (from February to October: about 9 months) and mixes only during the cold period, which implies a warm monomictic lake.

The lake Rabindra Sarobar exhibits anoxic conditions only during the peak summer which lie at a height of $0.5-0.75 \mathrm{~m}$ from the sediment-water interface. The oxic conditions usually occur up to a depth of $2-2.5 \mathrm{~m}$ from the water surface with hypoxic in between (i.e. within the oxycline layer). Over the years, the lake Rabindra Sarobar shows hypoxic conditions of dissolved oxygen excepting the summer season.

The average depth of anoxia in lake Subhas Sarobar is approximately 1.0 to $1.5 \mathrm{~m}$ from the lake bottom; however, the depth of the oxycline shows considerable short-term and long-term fluctuations above the anoxic layers and below the oxic layers (2.0-2.5 $\mathrm{m}$ from the lake surface). The oxygen level at the hypolimnion region continues to decrease to a value of $0.01 \mathrm{ppm}$ over years together with a due effect of increased air and surface water temperature in the lake.

The rate of oxygen depletion from the hypolimnion of Lake Subhas Sarobar is extremely high compared to the lake Rabindra Sarobar with respect to the in-lake depth effect and meteorological effects over the lake area.

Fish kills have been recorded in the lake Subhas Sarobar, called the "summer fish kill" due to the decreased vertical mixing based on the transport of oxygen from the epilimnion.

The lake Subhas Sarobar strongly experienced the effect of the Tsunami on 26th December 2004, indicated by elevated water temperature and oxygen levels ( $7.3 \mathrm{ppm}$ average) along the depth, observed on 31st December 2004, and which persisted until the last day of sampling (28th January 2005) in the limnological year. In particular, the formation of a hypolimnion oxygen minimum is of great importance for the fishery management.

\section{Acknowledgements}

We wish to express our gratitude to the DAAD, (Deutscher Akademischer Austausch Dienst) Bonn, Germany which financed (A/04/06852) the water quality modeling research carried out at the University of Konstanz, Germany as part of its developmental assistance during the tenure of the Fellowship. Financial support also came from the School of Water Resources Engineering, Jadavpur University in the form of study grant to the first author. The authors wish to thank the authorities of Kolkata Improvement Trust (KIT) for permitting and providing necessary facilities during field work at the Lake complex. The authors also acknowledge the team work that rendered by Prof. Dr. Balaram Bose and Dr. (Mrs.) Debasri Roy, School of Water Resources Engineering, Jadavpur University and Dr. Erich Bäuerle, Scientist, Wasseransichten, D-21369 Moislingen, Germany for their encouragement in this research work.

\section{References}

Cairns Jr., J., 1997. Sustainability, ecosystem services, and health . Int. J. Sustain. Dev. World Exol. 4, 153-165.

Goudsmit, G.H., Burchard, H., Peeters, F., Wüest, A., 2002. Application of $k$-e turbulence models to enclosed basins: The role of internal seiches. J. Geophys. Res., No. C12, 3230(23) $107,1-13$. 
Hutter, K., Jöhnk, K.D., 2004. Continuum methods of physical modelling-Continuum mechanics, dimensional analysis, turbulence. Springer-Verlag, Heidelberg.

Imberger, J., Patterson, J.C., 1981. A dynamic reservoir simulation model- DYRESM:5. In: H. B. Fischer (Ed.), Transport Models for Inland and Coastal waters, pp.310-361. Academic Press, London.

Jöhnk, K.D., Umlauf, L., 2001. Modelling the metalimentic oxygen minimum in a medium sized alpine lake. Ecol. Model. $136,67-80$.

Jorgensen, S.E., 1995b. The application of ecological indicators to assess the ecological condition of a lake. Lakes Reservoirs: Res. Manage. 1, 177-182.

Kraus, E.B., Turner, J.S., 1967 . A one-dimensional model of the seasonal thermocline - II. The general theory and its consequences. Tellus 19, 98-105.

Ostroumov, S.A., 2002. Inhibitory analysis of top-down control: new keys to studying eutrophication, algal blooms, and water self-purification. In: S.A. Ostroumov, S.C. McCutcheon and C.E.W. Steinberg (Eds.), Ecological Processes and Ecosystems, pp. 117-129. Hydrobiologia 469.

Ostroumov, S.A., 2002a. Polyfunctional role of biodiversity in processes leading to water purification: current conceptualizations and concluding remarks. In: S.A. Ostroumov, S.C. McCutcheon and C.E.W. Steinberg (Eds.), Ecological Processes and Ecosystems, pp. 203-204. Hydrobiologia 469 $1-3$.

Prepas E.E., Burke, J.M., 1997. Effects of hypolimnetic oxygenation on water quality in Amisk Lake, Alberta, a deep, eutrophic lake with high internal phosphorus loading rates, Can. J. Fish. Aquat. Sci.J. Can. Sci. Halieut. Aquat. 54(9), 2111-2120.

Rapport, D.J., Regier, H.A., Hutchinson, T.C., 1985. Ecosystem behavior under stress. Am. Naturalist 125, 617-640.

Rodi, W., 1993. Turbulence Models and their application to Hydraulics, 3rd edition. A.A. Balkema, Rotterdam.
Samal, N.R., 2004a. Study of morphometry and hydrothermal analysis of a tropical shallow Indian lake, report submitted to DAAD (A/04/06852), Bonn, Germany.

Samal, N.R., Roy, D., Mazumdar, A., Bose, B., 2004b. Infiuence of thermal stratification on Dissolved Oxygen in Subhas Sarobar, Kolkata., J. Current Sc. 7(1), 259266.

Samal, N.R., Mazumdar, A., 2005. Management of Lake Ecosystem. J. of The Ekologia 3(2), 123-130.

Samal, N.R., 2006. Study of morphometry and hydrothermal analysis of tropical shallow lake, $\mathrm{Ph} . \mathrm{D}$. Thesis, School of Water Resources Engineering, Jadavpur University, Kolkata, West Bengal, India

Samal, N.R., Jöhnk, K.D., Peeters, F., Bāuerle, E., Mazumdar, A., 2008. Mixing and internal waves in a small stratified Indian Lake: Subhas Sarobar. In: P.K. Mohanty (Ed.), Monitoring and Modelling Lakes and Coastal Environments, pp. 248. Springer Publishing, Berlin.

Simon, A., Kevln, T., Bolano, T., Wrigley, T. J., 1992. Factors contributing to a fish kill in the Australian wet/dry tropics, Wat. Res. 26(8), 1039-1044.

Svensson, U., 1978. A mathematical model of the seasonal thermocline. Dissertation, London.

Verburg, P., Hecky, R. E., Kling, H., 2003. Ecological consequences of a century of warming in Lake Tanganyika. Science 301, 505-507.

Xu, F.L., Jorgensen, S.E., Tao, S., 1999. Ecological indicators for assessing freshwater ecosystem health. Ecol. Model. 116 $77-106$.

Xu, F.L., Dawson, R.W., Tao, S., Cao, J., Li, B.G., 2001a. A Method for Lake Ecosystem Health Assessment: an Ecological Modeling Method (EMM) and Its Application. Hydrobiologia 443, 159-175.

Xu, F.L., Tao S., Dawson, R.W., Li, B.G., Cao, J., 2001b. Lake Ecosystem Health Assessment: Indicators and Methods.Water. Res. 35(13), 3157-3167. 